\title{
sciendo
}

\section{The Relative Age Effect in Poland's Elite Youth Soccer Players}

\author{
by \\ Krystian Rubajczyk ${ }^{1}$, Andrzej Rokita ${ }^{1}$
}

The relative age effect (RAE) is related to discrimination against youth athletes born in the last quarter of the calendar year. The current study presents research on the RAE in elite youth soccer players in Poland. Players in the Central Junior League (CLJ) finals represent $0.59 \%$ of the 25,756 players under 20 years old (U20). This study analyzed the post-game protocols of the CLJ knockout stage from the 2013/2014 and 2014/2015 seasons as well as the U17-U21 teams during 2015, including only players who played on the field for at least one minute $(n=395)$. The results revealed the existence of RAE in the examined groups (CLJ 2013/2014, $\chi^{23}=15.441, p<0.01, C L J$ 2014/2015, $\chi^{23}=20.891, p<0.001$ U17-U21, $\chi^{23}=25.110, p<0.001$ ). In addition, the results differed by monthly birth distribution in the Polish population (PP) between 1995 and 1999. This study is the first to examine the RAE in youth soccer in Poland. The occurrence of the RAE with regard to the most promising youth and national team players suggests that a similar effect exists among younger age categories. To reduce the RAE related to identifying soccer talent, tools should be implemented to optimize the player-selection process, such as those that consider the biological development of a player.

Key words: talent identification, selection, soccer.

\section{Introduction}

Differences in the biological development of children and adolescents indirectly determine the assessment of predispositions to play a particular sport. When evaluating the potential of a young athlete, his or her skills are compared within a peer group. However, the chronological age of this group can differ by over 11 months. This difference results in players who have both physical and mental advantages over their younger peers, and these youth are consequently selected more frequently, creating the phenomenon known as the relative age effect (RAE; Musch and Grondin, 2001).

Previous studies have identified the RAE in many individual sports including swimming (Costa et al., 2013; Medic et al., 2009), athletics (Romann and Cobley, 2015), and winter sports (Müller et al., 2015; Romann and Fuchslocher, 2014). This phenomenon has also been identified in team sports, especially those that value physical strength such as soccer (Augste and Lames, 2011; Diaz Del Campo et al., 2010; Helsen et al., 2012; Romann and Fuchslocher, 2013), basketball (Delorme and Raspaud, 2009; Schorer et al., 2011), handball (Delorme et al., 2009; Karcher et al., 2014), and hockey (Hancock et al., 2013; Stenling and Holmström, 2014). Furthermore, the RAE has been observed in volleyball, a non-contact team sport (Nakata and Sakamoto, 2011). Soccer requires high locomotive performance, physical strength and psychological maturity for player's decision making. One 90-minute game can include from 1,000 to 1,400 direction changes depending on the situation on the field (Stølen et al., 2005). As such, success is often determined by the efficiency of players' cognitive functions (Vestberg et al., 2012). Therefore, considerable differences in biological and psychological development might lead to misevaluations of the potential and dispositions

1 - Department of Team Games Sport, University School of Physical Education, Wroclaw, Poland. 
of youth soccer athletes. This RAE mechanism is relevant to youth soccer club coaches who focus on achieving "here and now" results (Tedesqui and Glynn, 2013). Another factor that might contribute to the RAE is the system of organizing youth games by chronological age. Frequently, players are subject to categorical groups according to a two-year birth span. As a result, the age difference between the oldest and youngest players can be up to 24 months.

Previous studies have identified the Matthew Effect and self-fulfilling prophecy as the theoretical mechanisms that underlie the RAE (Hancock et al., 2013). The Matthew Effect illustrates the role the accumulated biological advantage has for players born in the first quarter of the year compared to their peers. In addition, the self-fulfilling prophecy can be explained through the Pygmalion effect and the Galatea effect. To summarize, our false beliefs, can become a true behavior when they are fueled by other people. Furthermore, the interactions between these theories when placed within the same complementary model of interacting social factors might explain the scale of the RAE in sports (Diaz Del Campo et al., 2010; Hancock et al., 2013; Thompson et al., 2004). Therefore, the influence of the RAE might be stronger in youth soccer than in other team sports. The relationship between the efficiency of player's actions and levels of perceptive and cognitive skills might increase disparities in youth soccer. These effects result in the standard model of selection for European soccer teams that occurred for many years (Helsen et al., 2012).

In Poland (where the RAE has not yet been explored in research), soccer is the most popular sport for youth. The Polish Football Association (PZPN) has over 530,583 members; this constitutes $1.38 \%$ of the population of approximately 38 million. The organization of the Polish soccer competition system by two-year age categories may influence the RAE. The flagship project of the PZPN is the Central Junior League (CLJ), which aims to allow the best 18- to 20-yearold players to compete. Teams that qualify for CLJ through elimination receive the financial and logistic support that enables them to organize games in distant locations. The players at the CLJ knockout stage represent $0.39-0.78 \%$ (78-154 out of 19800 ) of all junior-level soccer players (U20).
Only the players at the highest level are selected for the under 17 years old (U17) and under 21 years old (U21) national teams. Although participation in the youth national teams does not guarantee later success, the early maturers have dominated national youth teams (Ostojic et al., 2014). In line with research by Augste and Lames (2011), the Polish youth topteams should consider the RAE phenomenon in the selection process, but above all, they must realize the scale of the problem.

Because of the significant influence of the RAE on the identification of young soccer talent in Europe, examining this phenomenon in Poland seems warranted. In line with this, the lack of clear data in this area, precludes the implementation of preventive procedures. Therefore, the present study aimed to determine the potential range of the RAE in elite youth soccer players within the CLJ and the reasons for this phenomenon.

\section{Methods}

\section{Sample and Data Collection}

Data on the birth dates of the players at the knockout stage of the CLJ and U17-U21 in 2015 were obtained from the official game records of the PZPN. The CLJ is the highest level of youth competitions in Poland, played throughout the whole country. The qualified teams of the 2013/2014 and 2014/2015 seasons represented the 12 best male U20 teams, which comprised 0.25 $0.5 \%$ (4-8 out of 1600 ) of all male teams of this category in Poland. The teams included 264 players in first-team squads and on the bench. The analysis focused on players who played for at least one minute in the knockout stage of the CLJ. To clearly refer to the phenomenon of RAE, the analysis excluded players not participating in the matches. The CLJ qualification scheme to the knockout stage is shown in Figure 1. Players selected for the national teams were included when they played for at least one minute on the field in an official national match.

The game records provided information on the birth day, month and year of players as well as the number of minutes they played in the CLJ knockout stage matches. Data concerning the monthly birth distribution of the Polish population (PP) of boys born between 1995 and 1999 were obtained from the Central Statistical Office of Poland. The average age of the CLJ and 
U17-U21 players in the selected sample was 19.2 years old $( \pm 0.8)$ and 18.7 years old $( \pm 1.6)$, respectively.

To identify the RAE, the players' dates of birth were assigned to the four quarters of the calendar year: Q1 (January to March), Q2 (April to June), Q3 (July to September), and Q4 (October to December). A similar procedure was applied to birth dates of the PP boys between 1995 and 1999, which corresponded to the birth dates of players at the CLJ knockout stage and the U17-U21 teams. All procedures were consistent with the Declaration of Helsinki and approved by the Research Ethics Committee of the University School of Physical Education in Wroclaw. The Polish Football Association made the data freely available in support of research on the RAE in Poland.

\section{Statistical Analysis}

Chi-squared tests $\left(\chi^{2}\right)$ were used to evaluate the significance of the inter-quartile differences for both populations; additionally the effect size $(\omega)$ was calculated. Cramer's V (V) was used for interpretation of medium (0.20-0.29) and large $(>0.30)$ effects. Odds ratios and 95\% confidence intervals (95\% CIs) were used to evaluate the differences in the quarterly distribution of birth dates. The KolmogorovSmirnov (K-S) tests were used to assess differences between the observed and expected monthly birth-date distributions. The calculations used a significance threshold of $\alpha=0.01$. All calculations were conducted using SPSS version 21.0 (IBM®, USA).

\section{Results}

The quarterly distribution of the birth dates of PP, players in the CLJ knockout stage and U17-U21 is presented in Table 1. In all groups examined the RAE was found (U17-U21, $p<0.001$,

CLJ 2013/2014, $p<0.01$, CLJ 2014/2015, $p<0.001$ ). A significant difference was observed between the number of players born in the first quarter of the year and both those born in the third and fourth quarter (Q1:Q3, $\chi^{2}=9.184, p=0.002 ; \chi^{2}=12.519, p$ $<0.001 ; \mathrm{Q} 1: \mathrm{Q} 4, \chi^{2}=27.272, p<0.001, \chi^{2}=31.873, p$ $<0.001)$. This result was also observed among U17-U21 players (Q1:Q4, $\chi^{2}=32.061, p<0.001$ ). Over $67 \%$ of players at the CLJ knockout stage during the 2013/2014 season and 78\% during the
2014/2015 season were born in the first half of the calendar year. The quarterly distribution of birth dates within the PP was nearly uniform; $51.29 \%$ of all boys births in 1995-1999 occurred in the first half of the year, and $22.38 \%$ occurred in the last quarter of the year. Of the U17-U21 players, only $27.22 \%$ were born in the second half of the calendar year. ORs, 95\% CIs, and effect sizes are presented in Table 2.

Figure 2 presents the monthly distribution of the birth dates of players at the CLJ knockout stage in 2013/2014 and 2014/2015, the players selected for the U17-U21 teams and the monthly seasonality of the births in Poland between 1995 and 1999. An irregular distribution of birth dates was observed for the CLJ players (2013/2014, $p$ $<0.01,2014 / 2015, p<0.01$ ), with decreases between May and June, from $12.66 \%$ to $5.06 \%$ during the $2013 / 2014$ season and from $12.66 \%$ to $6.33 \%$ during the $2014 / 2015$ season. Unlike the aforementioned distribution, the monthly distribution of birth dates of the PP was uniform in May, June, and July $(8.56 \%, 8.63 \%$, and 9.39\%, respectively), maintaining the same trend until the end of the year. An irregular distribution of birth dates was also observed among players selected for the U17-U21 $(p<0.01)$ teams in 2015 (May $=12.69 \%$, June $=6.49 \%$ ).

\section{Discussion}

The RAE has been previously observed in soccer in many nations, including several European countries (Augste and Lames, 2011; Horn and Okumura, 2011; Romann and Fuchslocher, 2013; Salinero et al., 2014). However, studies have not been conducted on the RAE in east Europe. Therefore, the present study aimed to identify the RAE in youth soccer in Poland. Furthermore, this study determined the possible scale and reasons for this phenomenon in elite youth soccer players.

The results of this study confirm that the RAE occurs in elite youth soccer players in Poland. Discrimination against players born in the last quarter of the year is visible even after taking into account lower fertility rates during this period in Poland. Nevertheless, a lower fertility rate in Poland in the last quarter of the year is a permanent phenomenon, unrelated to the number of active soccer players. The scale of the RAE related to elite youth soccer players in Poland is 
comparable with the research results concerning elite youth soccer teams in Germany and Switzerland (Augste and Lames, 2011; Romann and Fuchslocher, 2011). Furthermore, the monthly distribution of birth dates is specific to the countries of central Europe; for example, compared with the results of this study, the distribution of birth months differs in African countries, where the largest number of players were born in the last quarter of the year (Williams, 2010). However, it is difficult to interpret this phenomenon in Africa because of the impossibility of verifying birth dates based on official documents.

Table 1

Quarterly distribution of births of boys in Poland between 1995 and 1999 and the players of Central Junior League knockout stage and those called up for national teams U-17 - U-21 in 2015.

\begin{tabular}{|c|c|c|c|c|c|c|c|c|c|}
\hline $\begin{array}{l}\text { CALENDAR } \\
\text { YEAR }\end{array}$ & Q1 (\%) & $\begin{array}{l}\text { Q2 } \\
(\%)\end{array}$ & Q3 (\%) & $\begin{array}{l}\text { Q4 } \\
(\%)\end{array}$ & TOTAL & $\chi^{2} \underline{3}$ & $p$ & V & Effect: \\
\hline $\begin{array}{l}\text { KNOCKOUT } \\
\text { STAGE } \\
\text { (TOP } 8 \\
\text { )CENTRAL } \\
\text { JUNIOR } \\
\text { LEAGUE2013/2014 }\end{array}$ & $\begin{array}{c}64 \\
(40.51)\end{array}$ & $\begin{array}{c}43 \\
(27.22)\end{array}$ & $\begin{array}{c}34 \\
(21.52)\end{array}$ & $\begin{array}{c}17 \\
(10.76)\end{array}$ & 158 & 15.441 & $<0.01$ & 0.22 & medium \\
\hline $\begin{array}{l}\text { KNOCKOUT } \\
\text { STAGE } \\
\text { (TOP 4) } \\
\text { CENTRAL } \\
\text { JUNIOR LEAGUE } \\
\text { 2014/2015 }\end{array}$ & $\begin{array}{c}40 \\
(50.64)\end{array}$ & $\begin{array}{c}22 \\
(27.85)\end{array}$ & $\begin{array}{c}14 \\
(17.72)\end{array}$ & $3(3.79)$ & 79 & 20.891 & $<0.001$ & 0.36 & large \\
\hline $\begin{array}{l}\text { CALL-UPS FOR } \\
\text { NATIONAL } \\
\text { TEAMS } \\
\text { U-17 - U } 21 \text { IN } \\
2015\end{array}$ & $\begin{array}{c}56 \\
(35.44)\end{array}$ & $\begin{array}{c}59 \\
(37.34)\end{array}$ & $\begin{array}{c}33 \\
(20.89)\end{array}$ & $10(6.33)$ & 158 & 25.110 & $<0.001$ & 0.28 & medium \\
\hline BIRTHS IN 1995 & $\begin{array}{c}56391 \\
(25.42)\end{array}$ & $\begin{array}{l}58503 \\
(26.37)\end{array}$ & $\begin{array}{l}59375 \\
(26.76)\end{array}$ & $\begin{array}{l}45574 \\
(21.45)\end{array}$ & 219843 & 1175.81 & $<0.001$ & 0.05 & \\
\hline BIRTHS IN 1996 & $\begin{array}{l}55624 \\
(25.21)\end{array}$ & $\begin{array}{l}57381 \\
(26.00)\end{array}$ & $\begin{array}{l}57915 \\
(26.24)\end{array}$ & $\begin{array}{l}49765 \\
(22.55)\end{array}$ & 220685 & 50.43 & $<0.001$ & 0.01 & \\
\hline BIRTHS IN 1997 & $\begin{array}{c}54023 \\
(25.44)\end{array}$ & $\begin{array}{c}55512 \\
(26.14)\end{array}$ & $\begin{array}{c}54732 \\
(25.78)\end{array}$ & $\begin{array}{c}48077 \\
(22.64)\end{array}$ & 212344 & 335.54 & $<0.001$ & 0.03 & \\
\hline BIRTHS IN 1998 & $\begin{array}{l}51250 \\
(25.13)\end{array}$ & $\begin{array}{l}52319 \\
(25.65)\end{array}$ & $\begin{array}{l}53948 \\
(26.45)\end{array}$ & $\begin{array}{l}46428 \\
(22.76)\end{array}$ & 203945 & 58.42 & $<0.001$ & 0.02 & \\
\hline BIRTHS IN 1999 & $\begin{array}{l}49520 \\
(25.21)\end{array}$ & $\begin{array}{l}50682 \\
(25.80)\end{array}$ & $\begin{array}{l}51888 \\
(26.42)\end{array}$ & $\begin{array}{l}44321 \\
(22.57)\end{array}$ & 196411 & 348.32 & $<0.001$ & 0.03 & \\
\hline
\end{tabular}

$\chi^{2} \underline{3}-$ chi-squared test value, $p$ - probability value, $V$-Cramer`s $V$ value 
Table 2

Differences in quarterly distribution of dates of birth of the players of knockout stage of Central Junior League 2013/2014 and 2014/2015, and those called up for national teams U-17 - U-21 in 2015.

\begin{tabular}{|c|c|c|c|c|}
\hline Sample: & & Q1:Q2 & Q1:Q3 & Q1:Q4 \\
\hline \multirow{5}{*}{$\begin{array}{l}\text { Players of knockout } \\
\text { stage of Central } \\
\text { Junior League } \\
\text { 2013/2014 }\end{array}$} & $\chi^{2}$ & 4.121 & 9.184 & 27.272 \\
\hline & $p$ & 0.042 & 0.002 & $<0.001$ \\
\hline & $\omega$ & 0.16 & 0.24 & 0.41 \\
\hline & OR & 1.820 & 2.483 & 5.647 \\
\hline & $\begin{array}{l}95 \% \\
\text { CI }\end{array}$ & $1.134-2.921$ & $1.513-4.072$ & $3.114-10.239$ \\
\hline \multirow{5}{*}{$\begin{array}{l}\text { Players of knockout } \\
\text { stage of Central Junior } \\
\text { League 2014/2015 }\end{array}$} & $\chi^{2}$ & 5.226 & 12.519 & 31.873 \\
\hline & $p$ & 0.022 & $<0.001$ & $<0.001$ \\
\hline & $\omega$ & 0.26 & 0.40 & 0.63 \\
\hline & OR & 2.657 & 4.762 & 25.982 \\
\hline & $\begin{array}{l}95 \% \\
\text { CI }\end{array}$ & $1.372-5.1450$ & $2.302-9.848$ & $7.556-89.351$ \\
\hline \multirow{5}{*}{$\begin{array}{l}\text { Players selected for } \\
\text { national teams } \\
\text { U-17 - U-21 }\end{array}$} & $\chi^{2}$ & -0.078 & 5.944 & 32.061 \\
\hline & $p$ & 0.78 & 0.015 & $<0.001$ \\
\hline & $\omega$ & 0.02 & 0.19 & 0.45 \\
\hline & OR & 0.921 & 2.078 & 8.125 \\
\hline & $\begin{array}{l}95 \% \\
\text { CI }\end{array}$ & $0.582-1.457$ & $1.125-3.440$ & $3.960-16.667$ \\
\hline
\end{tabular}

$\chi^{2}$ - chi-squared test value, $p$ - probability value, $\omega$-effect size measure, OR - odds ratio, $95 \%$ CI- 95\% confidence interval. 


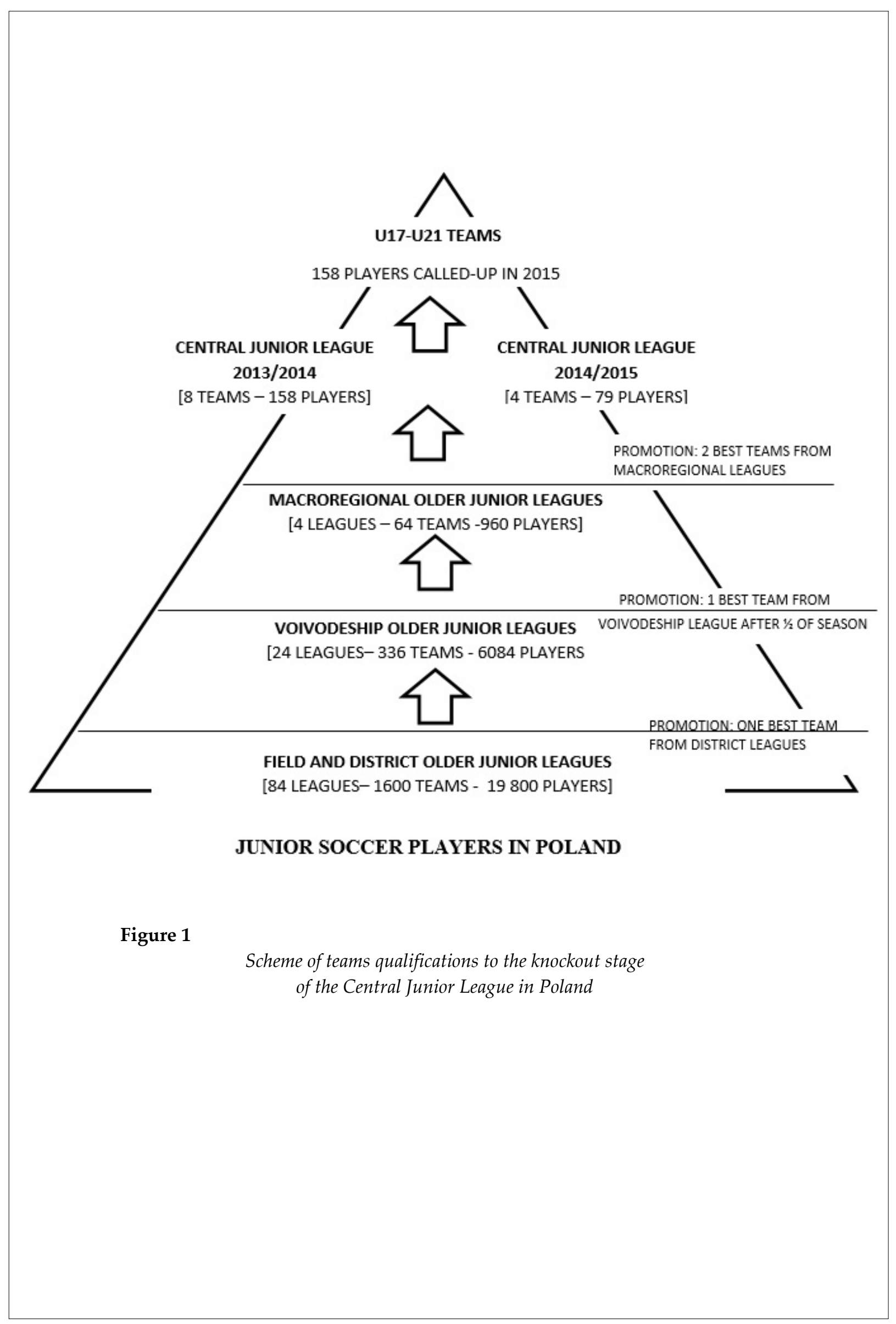




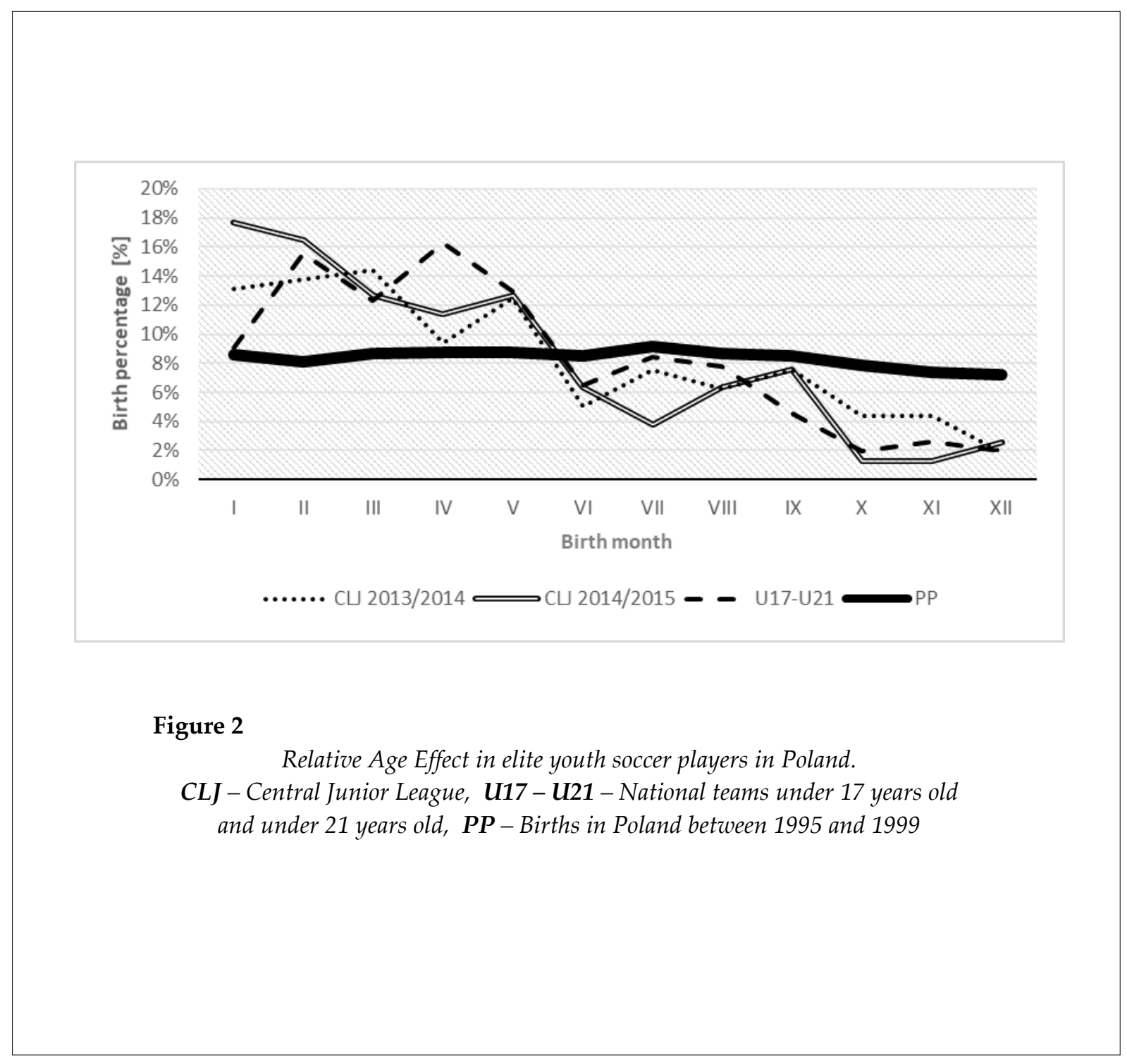

The mechanisms of the RAE in Poland appear to be similar to those observed in other countries. Coaches, players and parents are involved in numerous social interactions that can, in many cases, result in an excessive focus on the present results of a sports team (Hancock et al., 2013). In this case, however, the most important element of social interaction is most likely a coach who manages the soccer talent identification process. This finding is in accordance with that of Cushion et al. (2012) concerning the significant difference between coaches' education and their actual behavior in soccer practice. Identifying and preventing the problem of RAE require time and practice. Inclusion of this issue in the programs of coaching courses is considered appropriate.

One of the reasons for the RAE in Polish soccer might be the categorization of players by chronological age from January 1 to December 31. The cut-off date system is in accordance with the 1997 guidelines of the European Union Football Association (UEFA). Nevertheless, game categories group together players based on twoyear birth periods, leaving coaches with considerable disparities among their trainees' physiques. Significant relationships have been reported among body composition, coordination and motor skills, and the selection process in soccer (Vandendriessche et al., 2012). Therefore, a more comprehensive approach is required to eliminate the influence of the RAE on player's evaluation.

In Poland, highly developed mechanisms enable children to participate in school sports 
through selected groups. Access to the extracurricular physical education classes is often more difficult for less talented children. This finding corroborates reports from other countries on children resigning from physical activity because of the RAE (Wattie et al., 2012). In addition, researchers indicate that socioecological factors (e.g., the average wage of parents) predict quitting sports among youth (Vella et al., 2014).

The unique value of this study lies in the fact that it is the first to examine the RAE among elite soccer players in a country of over 38 million people. Detecting weaknesses in the proper identification of soccer talent should enable the implementation of practices to reduce the scale of the RAE. One such measure should be educating coaches in Poland on the RAE in addition to preventive measures such as determining player's biological age.

\section{Study Limitations}

This study has several limitations. The first is the presentation of the RAE from the perspective of only elite youth soccer players without addressing its presence at other CLJ game stages. The second limitation is the lack of the relationship between the scale of the RAE and the number of minutes or a position played (Romann and Fuchslocher, 2011).

\section{Conclusions}

The major achievement of this study is its identification of the RAE in Polish youth soccer. The results are of importance for coaches working with youth players to create a more comprehensive player evaluation that considers biological development. Future research is required to develop tools that take into account the RAE to optimize soccer talent identification. In addition, identifying the RAE in other age categories of youth soccer in Poland is crucial.

\section{Acknowledgements}

The authors would like to express their thanks to Konrad Kowalski and Łukasz Wachowski (Polish Football Association) for their kind assistance within the project.

\section{References}

Augste C, Lames M. The relative age effect and success in German elite U-17 soccer teams. J Sport Sci, 2011; 29: 983-987

Costa AM, Marques MC, Louro H, Ferreira SS, Marinho DA. The relative age effect among elite youth competitive swimmers. European Journal of Sport Science, 2013; 13: 437-444

Cushion C, Ford PR, Williams AM. Coach behaviours and practice structures in youth soccer: implications for talent development. J Sport Sci, 2012; 30: 1631-1641

Delorme N, Boiché J, Raspaud M. The relative age effect in elite sport: the French case. Res Q Exercise Sport, 2009; 80: 336-344

Delorme N, Raspaud M. The relative age effect in young French basketball players: a study on the whole population. Scand J Med Sci Spor, 2009; 19: 235-242

Diaz Del Campo DG, Vicedo JCP, Villora SG, Jordan ORC. The relative age effect in youth soccer players from Spain. Journal Sports Science \& Medicine, 2010; 9: 190-198

Hancock DJ, Seal K, Young BW, Weir PL, Ste-Marie DM. Examining mechanisms that contribute to relative age effects in pre-pubescent female ice hockey players. Talent Development \& Excellence, 2013; 5: 59-66

Helsen WF, Baker J, Michiels S, Schorer J, Van Winckel J, Williams AM. The relative age effect in European professional soccer: did ten years of research make any difference? J Sport Sci, 2012; 30: 1665-1671

Horn RR, Okumura M. It's time to eliminate the relative age effect in American soccer. Soccer Journal, 2011; 56: $38-40$

Karcher C, Ahmaidi S, Buchheit M. Effect of birth date on playing time during International handball competitions with respect to playing positions. Kinesiology, 2014; 46: 23-32

Medic N, Starkes JL, Weir PL, Young BW, Grove JR. Relative age effect in masters sports: replication and 
extension. Res Q Exercise Sport, 2009; 80: 669-675

Müller L, Hildebrandt C, Raschner C. The relative age effect and the influence on performance in youth alpine ski racing. Journal Sports Science \& Medicine, 2015; 14: 16-22

Musch J, Grondin S. Unequal competition as an impediment to personal development: a review of the relative age effect in sport. Dev Rev, 2001; 21: 147-167

Nakata H, Sakamoto K. Relative age effect in Japanese male athletes. Percept Motor Skill, 2011; 113: 570-574

Ostojic SM, Castagna C, Calleja-González J, Jukic I, Idrizovic K, Stojanovic M. The biological Age of 14-yearold boys and success in adult soccer: do early maturers predominate in the top-level game? Research in Sports Medicine, 2014; 22: 398-407

Romann M, Cobley S. Relative Age effects in athletic sprinting and corrective adjustments as a solution for their removal. PLOS ONE, 2015; 10: e0122988

Romann M, Fuchslocher J. Influence of the selection level, age and playing position on relative age effects in Swiss women's soccer. Talent Development \& Excellence, 2011; 3: 239-247

Romann M, Fuchslocher J. Relative age effects in Swiss junior soccer and their relationship with playing position. European Journal of Sport Science, 2013; 13: 356-363

Romann M, Fuchslocher J. Survival and success of the relatively oldest in Swiss youth skiing competition. International Journal of Sports Science and Coaching, 2014; 9: 347-356

Salinero JJ, Pérez B, Burillo P, Lesma ML, Herrero MH. The relative age effect in Spanish professional football. Revista Internacional de Medicina y Ciencias de la Actividad Física y del Deporte, 2014; 14: 591601

Schorer J, Neumann J, Cobley S, Tietjens M, Baker J. Lingering effects of relative age in basketball players' post athletic career. International Journal of Sports Science and Coaching, 2011; 6: 143-148

Stenling A, Holmström S. Evidence of relative age effects in Swedish women's ice hockey. Talent Development E Excellence, 2014; 6: 31-40

Stølen T, Chamari K, Castagna C, Wisløff U. Physiology of soccer: an update. Sports Med, 2005; 35: 501-536

Tedesqui RAB, Glynn BA. "Focus on What?": applying research findings on attentional focus for elite-level soccer coaching. Journal of Sport Psychology in Action, 2013; 4: 122-132

Thompson AH, Barnsley RH, Battle J. The relative age effect and the development of self-esteem. Educ Res, 2004; 46: 313-320

Vandendriessche JB, Vaeyens R, Vandorpe B, Lenoir M, Lefevre J, Philippaerts RM. Biological maturation, morphology, fitness, and motor coordination as part of a selection strategy in the search for international youth soccer players (age 15-16 years). J Sport Sci, 2012; 30: 1695-1703

Vella SA, Cliff DP, Okely AD. Socio-ecological predictors of participation and dropout in organised sports during childhood. International Journal of Behavioral Nutrition and Physical Activity, 2014; 11: 1-20

Vestberg T, Gustafson R, Maurex L, Ingvar M, Petrovic P. Executive functions predict the success of topsoccer players. PLOS ONE, 2012; 7: e34731

Wattie N, Schorer J, Tietjens M, Baker J, Cobley S. Relative age effects in higher education: an investigation of potential Long term impacts resulting from youth sport and education policies. Talent Development $\mathcal{E}$ Excellence, 2012; 4: 49-63

Williams JH. Relative age effect in youth soccer: analysis of the FIFA U17 World Cup competition. Scand J Med Sci Sports, 2010; 20: 502-508

\section{Corresponding author:}

\section{Krystian Rubajczyk,}

Department of Team Games Sport, University School of Physical Education, Wroclaw, Poland,

Phone: + 48697319807 Fax: + 48713473562 .

E-mail: krystian.rubajczyk@gmail.com 